\title{
CLARA SADOUN-ÉDOUARD, Le roman de «La Vie parisienne» (1863-1871)
}

\section{Ida Merello}

\section{OpenEdition}

\section{Journals}

\section{Edizione digitale}

URL: http://journals.openedition.org/studifrancesi/16598

DOI: 10.4000/studifrancesi. 16598

ISSN: 2421-5856

\section{Editore}

Rosenberg \& Sellier

\section{Edizione cartacea}

Data di pubblicazione: 1 juillet 2019

Paginazione: 183

ISSN: 0039-2944

\section{Notizia bibliografica digitale}

Ida Merello, «CLARA SADOUn-ÉdouARD, Le roman de «La Vie parisienne» (1863-1871)», Studi Francesi [Online], 187 (LXIII | I) | 2019, online dal 01 juillet 2019, consultato il 25 janvier 2021. URL: http://

journals.openedition.org/studifrancesi/16598 ; DOI: https://doi.org/10.4000/studifrancesi. 16598

Questo documento è stato generato automaticamente il 25 janvier 2021.

\section{(@) $\odot \Theta \Theta$}

Studi Francesi è distribuita con Licenza Creative Commons Attribuzione - Non commerciale - Non opere derivate 4.0 Internazionale. 


\title{
CLARA SADOUN-ÉDOUARD, Le roman de «La Vie parisienne» (1863-1871)
}

\author{
Ida Merello
}

\section{NOTIZIA}

CLARA SADOUN-ÉDOUARD, Le roman de «La Vie parisienne» (1863-1871), Paris, Champion 2018, $561 \mathrm{pp}$.

Opera di proporzioni monumentali, anche per la quantità dei punti di vista prospettici, il lavoro compie una ricognizione del settimanale La Vie parisienne, dalla nascita alla morte, attraverso le figure dei suoi direttori e le peripezie di una pubblicazione che nasconde, sotto la continuità del titolo, una sostanziale varietà di obiettivi e di contenuti, dalle origini con articoli di Mallarmé fino alle conclusioni come rassegna di proposte di prestazione sessuale. Gli studiosi si erano inoltre già accorti di come il titolo, sovrapponibile a quello dell'opera buffa di offenbach, avesse nociuto anche all'identificazione della specificità della rivista originaria, nascosta sotto una sorta di marchio diffuso e di rinvio a un mito. Forte di una ricchissima bibliografia, l'A. mostra la nascita della rivista, soffermandosi a lungo, con ricchezza di documenti, sui diversi direttori, dalla figura prestigiosa del primo, Marcelin, fino all'ultimo, Georges Ventillard, cercando di seguire da vicino la linea editoriale della testata e la sua evoluzione. L'importanza sotto il secondo Impero è testimoniata anche dal ruolo di diffusione del gusto nelle rubriche di critica d'arte. Più complicato rintracciare tutti i collaboratori, spesso nascosti sotto diversi pseudonimi, al fine di moltiplicare talvolta la voce di una sola persona. Largo spazio è attribuito a Gustave Droz, giornalista dimenticato e tuttavia penna di punta sotto il secondo impero. Ma anche in seguito la rivista non perde la sua capacità di interpretare e seguire i gusti del pubblico. Il fatto che lo stesso Trotzkij, in esilio a Parigi, avesse fatto proprio un'analisi di La Vie parisienne, rivela la sua significatività come sismografo parigino. 
2 La maggior parte del corpus analizzato dall'A. riguarda comunque la prima epoca della rivista, dal punto di vista della nozione di galanteria (e con un confronto con La Dernière mode di Mallarmé) e del modo di parlare del mondo femminile. La lettura si mostra ricca di conclusioni: un giornale alla moda può trasformarsi in icona, diventare fucina per gli scrittori che entrano nel mondo letterario, interagire con esso, contribuendone all'affermazione. Per questo il giudizio di Valéry, in apparenza sconcertante ("première revue au monde"), trova la sua giustificazione. 